\title{
A importância do Título de Especialista
}

A legislação no Brasil faculta ao indivíduo portador de registro no Conselho Regional de Medicina realizar qualquer procedimento médico, independente da especialidade, complexidade e repercussões clínicas. Obviamente, é impossível para qualquer médico desenvolver simultaneamente com competência, segurança e responsabilidade procedimentos tão diversos como clinicar, executar exames complementares e cirurgias em cardiologia, gastroenterologia, neurologia, etc. O Título de Especialista constitui a forma oficial de reconhecer o profissional médico com formação acadêmico-científica adequada e apto a exercer uma especialidade com ética, responsabilidade e competência.

O Título de Especialista somente pode ser emitido pela Sociedade de Especialidade formalmente ligada à Associação Médica Brasileira (AMB) e o processo de avaliação e concessão do Título deve atender às exigências estabelecidas no convênio firmado pela AMB e Conselho Federal de Medicina em 10/02/89 e na Normativa de Regulamentação para Obtenção de Títulos Especialista da AMB datada de 27/03/98. A Sociedade Brasileira de Medicina do Esporte (SBME) é o órgão oficialmente autorizado a conceder o Título de Especialista em Medicina do Esporte (TEME) e recentemente estabeleceu suas normas que estão publicadas neste número da RBME. A prova para concessão do TEME ocorre uma vez por ano e em 2000 a prova escrita acontecerá em São Paulo, SP, no dia 13 de abril, das 16 às 19 horas, no Instituto Dante Pazzanese de Cardiologia, durante o IV Congresso Paulista e IV Jornada Internacional de Medicina do Esporte - II Simpósio Dante Pazzanese de Cardiologia do Esporte - I Simpósio de Traumatologia do Esporte. O edital completo está sendo publicado neste número da RBME e está também disponível na homepage da SBME (http://pagina.de/sbme) e nas Sociedades Regionais filiadas à SBME.

A obtenção do TEME representa a conquista do reconhecimento oficial da formação e habilitação especializada do médico, cujas repercussões profissionais têm-se tornado cada vez mais evidentes com a crescente valorização do Título pelas empresas de seguro e planos de saúde e pela sociedade de um modo mais amplo. Além disso, a posse do TEME credencia o médico a participar mais ativamente da SBME. Por exemplo, segundo o estatuto vigente da SBME e a Normatização publicada neste número da revista, somente portadores do TEME podem ser candidatos ao cargo de Presidente da SBME ou integrar comissões como a do Título de Especialista em Medicina do Esporte e Reconhecimento de Cursos de Especialização em Medicina do Esporte, funções-chave no desenvolvimento da nossa especialidade.

Portanto, convidamos os médicos praticantes de Medicina do Esporte que atendam às condições descritas no edital a participar da próxima prova de TEME com a expectativa de que tenhamos cada vez mais colegas habilitados para contribuir na ampliação e intensificação das atividades da SBME, com consequiente fortalecimento e crescimento qualificado da Medicina do Esporte no Brasil.

\author{
Antonio Claudio Lucas da Nóbrega \\ Editor Associado RBME \\ Presidente da Comissão do Título de \\ Especialista em Medicina do Esporte - SBME
}

Rev Bras Med Esporte - Vol. 6, № $1-\mathrm{Jan} / \mathrm{Fev}, 2000$ 